Mediaciones Sociales

ISSN-e: 1989-0494

EDICIONES

http://dx.doi.org/10.5209/MESO.58121

COMPLUTENSE

\title{
Homenaje a Todorov
}

Todorov, Tzvetan y otros (1988) Cruce de culturas y mestizaje cultural. Ediciones Júcar. Colección Júcar Universidad. Serie Antropología, $2^{\mathrm{a}}$ edición $\left(1986,1^{\mathrm{a}}\right.$ ed.). pp 322. ISBN: 10: 8433470175. ISBN 13: 9788433470171.

Tzvetan Todorov falleció en París el pasado 7 de febrero de 2017. La contribución de su obra a las ciencias de la cultura y de la comunicación es bien conocida y apreciada en muchas universidades del mundo, instituciones culturales y organizaciones de la sociedad civil. Precisamente, cuando le fue concedido en España el Premio Príncipe de Asturias de Ciencias Sociales (2008), el jurado declaró que su obra representaba «el espíritu de la unidad de Europa, del Este y del Oeste, y el compromiso con los ideales de libertad, igualdad, integración y justicia».

Varios de sus estudios sobre la mediación en las relaciones interculturales son una referencia en este ámbito especialmente complejo, tanto desde el punto de vista teórico como del político. A todos los interesados en este campo conocen algunos de sus títulos,

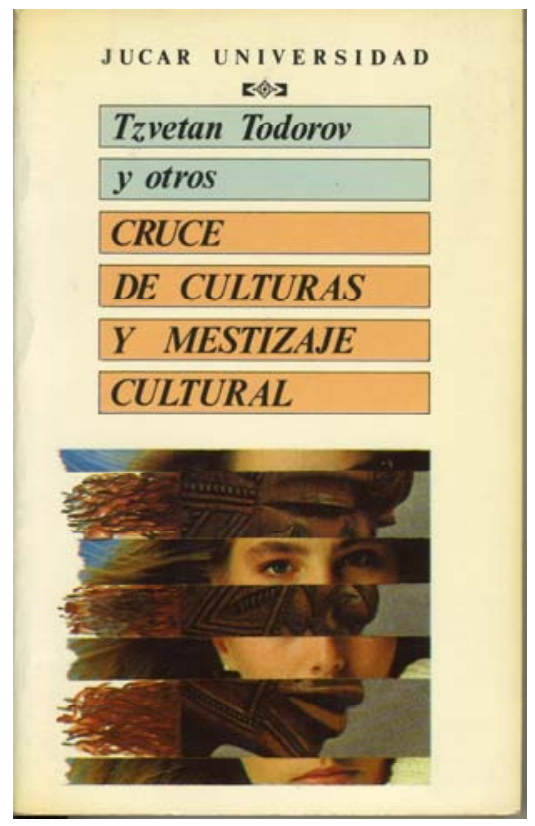
tales como: La conquista de América, la cuestión del otro (1982); Relatos aztecas de la conquista, con Georges Baudot (1983); Nosotros y los otros (1989); La vida en común (1995); El jardín imperfecto: luces y sombras del pensamiento humanista (2008); Memoria del mal, tentación del bien. Indagación sobre el siglo $X X$ (2002); El nuevo desorden mundial. Reflexiones de un europeo (2008); El miedo a los bárbaros, más allá del choque de civilizaciones (2008); Muros caídos, muros erigidos (2011); Vivir solos juntos (2011).

En homenaje a su memoria, reseñamos aquí su obra temprana, Le croisement des cultures, publicada en francés por Editions du Seuil, en 1986, y dos años después en castellano, por Ediciones Júcar, Cruce de Culturas y Mestizaje cultural 
$(1988)^{1}$. Este libro colectivo, coordinado por Todorov desde la institución académica que dirigió hasta su muerte, el Centro de Investigaciones sobre las Artes y el Lenguaje, del CNRS (Centro Nacional de Investigación Científica), de Francia, nos ofreció un estado de la cuestión, hace 30 años, sobre este asunto tan complejo de nuestros días, el tiempo de la globalización, que afecta a nuestra vidas cotidianas como a diversas disciplinas científicas. En la contraportada de la publicación de Ediciones Júcar se resume el tema de un modo breve, preciso y conciso:

«La cultura mundial de hoy dominada por Occidente, hecha de restos de las culturas autóctonas anteriores, aculturaciones fallidas, interconexiones globales equívocas, un leve barniz tecnológico occidental, y en general un cosmopolitismo de desechos, es el tema que concierne a los artículos reunidos en este libro.

Es una problemática que invade nuestra cotidianidad inmediata, en la forma de los contactos turísticos y la convivencia con los nuevos inmigrantes del Tercer Mundo, pero también en la forma mediática y envolvente de los documentales y noticias, de las películas y telefilmes que nos hablan de un mundo distorsionado a escala global, donde pueblos y culturas conviven todos a un tiempo sin entenderse.

Es también la problemática específica de una antropología que ya no encuentra pueblos exóticos en estado puro, sino sólo restos de culturas en putrefacción, integradas de la peor manera posible en el gran cuerpo de la cultura-mundo actual.

Cruce, pues, de culturas, en el sentido de su hibridación, y mestizaje de etnias, con los malentendidos, desigualdades e inadecuaciones que ello comporta: tal es la realidad vivida de la sociedad interconectada, telematizada, casi homogénea, que la ideología tecnotrónica dominante intenta hacernos creer. Es esta realidad de lo heterogéneo mal avenido la que, en forma de análisis antropológicos, ensayos críticos, testimonios de vida y consideraciones lingüísticas, pretende vehicular críticamente este volumen».

Precisamente, estas realidades de «lo heterogéneo mal avenido» es el objeto sobre el que operan las prácticas sociales de mediación (discursivas o políticoprácticas), para establecer modelos normativos de lo que puede ser y no ser pensado, dicho y hecho. La investigación científica y la crítica intelectual se ocupa en desvelar esos modelos, su lógica de construcción y sus usos sociales.

1 Todorov, Tzvetan et al. (1988). Cruce de Culturas y Mestizaje cultural. Madrid, Ediciones Júcar, Colección Júcar Universidad, Serie Antropología, 2a edición (1986, 1ª ed.). Pp. 322. ISBN 10: 8433470175. ISBN 13: 9788433470171 . 
Como suele suceder con los libros de este tipo, las perspectivas científicas y los puntos de vista son diversos; asimismo, la talla teórica o metodológica de los estudios. Está organizado en cuatro secciones.

1) Cuatro estudios sobre disciplinas que tienen por uno de sus objetos el cruzamiento entre culturas:

- La filosofía política: Luc Ferry y Alain Renaut. El fundamento universal de los derechos humanos (pp. 37-70). (pp. 71-89).

- La historia: François Hartog: El ojo del historiador y la voz de la historia

- La etnología: Clifford Geertz. Diapositivas antropológicas (pp. 91-114).

- La antropología (estudio comparado de las culturas): François Jullien. El mayor rodeo: La sinología como disciplina occidental (pp. 115-127).

2) Dos estudios que evocan a tres autores que observaron de cerca y reflexionaron sobre el cruzamiento cultural para tratar de comprenderlos:

- Abdelwahab Meddeb. La religión del otro: Ibn 'Arabí / Ramón Llull (pp. 131-144). Ibn Arabi fue un filósofo musulmán, nacido en Murcia, de la antigua AlÁndalus, de padre murciano y madre bereber; vivió entre los siglos XII y XIII. Ramon Llull o Raimundo Lulio (el «Arabicus Christianus») fue uno de los filósofo más avanzados del siglo XIII, nació en Mallorca, bajo la Corona de Aragón, y fue uno de los primeros autores en utilizar el catalán escrito.

- Pascal Bruckner. V. S. Naipul, o el cosmopolitismo como detritus (pp. 147-158). V. S. Naipul, escritor británico, premio Nobel de Literatura en 2001. Nació en 1932, en Trinidad y Tobago, de padres hindúes inmigrantes.

3) Cinco estudios, no ya de los discursos sobre el cruzamiento, sino del cruzamiento mismo:

- Louis Dumont. El individuo y las culturas, o cómo la ideología se modifica por su misma difusión (pp. 159). Analiza la interacción cultural desde la oposición entre sociedades holísticas y sociedades individualistas.

Los demás estudios se ocupan de aspectos muy particulares de la interacción cultural: aculturación de trabajadores emigrantes; turismo internacional e identidad cultural; lenguas extranjeras; traducción.

4) Dos reflexiones de los autores sobre sus experiencias personales: bilingüismo, exilio.

En esta reseña nos ocupamos principalmente del trabajo introductorio de Tzvetan Todorov. 


\section{De las perspectivas de los discursos sobre el cruzamiento de las culturas}

Todorov reconoce la amplia documentación y la legitimidad de las diversas perspectivas científicas que estudian el cruzamiento entre culturas. Así, por ejemplo:

- Sociología: Estudio de los efectos de cohabitación de múltiples grupos culturales en un mismo suelo o bien las formas de aculturación que sufre una población de emigrantes.

- Literatura: Estudio de la influencia entre autores o escuelas literarias o de los efectos de un ambiente bilingüe en un autor determinado.

- Historia: Estudio de las consecuencias de las invasiones extranjeras en una sociedad y período determinado.

- Epistemología: Estudio sobre la especificidad del conocimiento etnológico o por la posibilidad de comprender a quien es distinto a mí.

Sin embargo, Todorov estima que la actitud científica resulta incompleta para ocuparse de este objeto. "Porque en estas investigaciones no se habla de sustancias físicas ni químicas, sino de seres humanos; y el racismo, el antisemitismo, los trabajadores emigrantes, los umbrales de tolerancia, el fanatismo religioso, la guerra y el etnocidio son nociones cargadas de un gran peso afectivo, respecto a las cuales es inútil aparentar indiferencia” (p. 9).

Igualmente legítima es la postura del hombre de acción, del militante, del político.

No obstante, Todorov estima que ambas actitudes, la científica y la militante, "padecen por igual un mutuo aislamiento". Su relación más corriente es la alternancia: "erudito de nueve a cinco y militante de cinco a nueve".

Esta afirmación no le sirve de pretexto para introducir las conocidas disquisiciones dialécticas sobre este asunto, sino para reivindicar la "desvalorizada" función del intelectual.

«Yo querría que en este momento se entendiera, mediante esta palabra, la necesidad que pesa sobre el especialista en el espíritu humano y sobre sus obras de dar cuenta de los valores que subyacen a su trabajo y de la relación que éstos guardan con los valores de su sociedad. El intelectual, en tanto que tal, no es un hombre de acción: incluso en el caso de que actúe adicionalmente, no (lo) es (...) por los servicios que preste a la Administración ni por la lucha clandestina que lleve a cabo. El hombre de acción parte de valores que da por supuestos; por el contrario, para el intelectual constituyen el objeto mismo de su reflexión. Su función es esencialmente crítica, pero en el sentido constructivo de la palabra: compara lo particular, en lo que todos vivimos, con lo universal y crea un espacio en el que todos podemos debatir la legitimidad de nuestros valores. Se niega a ver cómo la verdad se reduce a la mera adecuación a los hechos, que 
constituye la aspiración del científico, o a la verdad de la revelación, que es la fe del militante; el intelectual pretende, sobre todo, una verdad consensuada, hacia la que se avanza aceptando el examen reflexivo y el diálogo.

Así pues, entreveo un objetivo común a las artes y a las ciencias humanas (que por otra parte operan con formas y discursos tan distintos): revelar y, si hay ocasión, modificar el complejo de valores que sirve de principio regulador de la vida de un grupo cultural». (p. 10-11).

Como ya se puede sospechar, la actitud explícita que adopta Todorov en su ensayo introductorio es la del intelectual. En este sentido resulta distinta y complementaria a la actitud de los otros autores que conforman este libro. Todorov organiza su exposición en torno a dos temas principales: los juicios sobre los otros y las interacciones con los otros.

\section{Juicio sobre los otros: La crítica de sus valores}

Los juicios culturales sobre los otros que resultan predominantes (y hasta de consecuencias fatales), son la xenofilia y la xenofobia.

- La xenofilia, en tanto simpatía por lo extranjero, presenta dos variantes:

- Malinchismo: Cuando el extranjero en cuestión pertenece a una cultura globalmente percibida como superior;

- Buen salvaje: Cuando la cultura extranjera es inferior a la propia y se admira precisamente en razón de su primitivismo, de su retraso, de su inferioridad tecnológica.

- La xenofobia, en tanto rechazo a todo lo extranjero, no conoce variantes.

Xenofilia y xenofobia, sin embargo, tienen un substrato común: la relatividad de los valores en que se basan; "solamente se es extranjero a ojos de los autóctonos, no se trata de ninguna cualidad intrínseca» (p. 14. El subrayado es nuestro).

Todorov sostiene que otro tanto podría decirse del principio de la tolerancia (tolerancia ¿con qué?), de la caridad cristiana y la piedad hacia los débiles y los vencidos: «sería injusto afirmar que los débiles siempre tienen razón debido a su misma debilidad: una situación transitoria, un accidente histórico, se eleva a la categoría de rasgo constitutivo» (p. 15).

Es la relatividad, precisamente, de estos valores la que no permite considerarlos como fundamentos del discernimiento. Este requiere de principios absolutos: «igualdad jurídica de todos los seres humanos o bien el carácter inviolable de las personas» (idem).

No obstante, Todorov estima que la piedad y la caridad, la tolerancia y la xenofilia no deben descartarse radicalmente: «los principios son abstractos y su aplicación plantea problemas; es probable que se tarde tiempo en resolverlos; 
mientras tanto es sin duda preferible ejercer la tolerancia que la justicia sumaria. En otras ocasiones, está claro quien tiene la razón; sin embargo, también pesan la miseria, el desamparo y el dolor, y hay que tenerlos en cuenta. Permitir que el comportamiento cotidiano sólo se guíe por principios abstractos conduce muy pronto a los excesos del puritanismo, en que se veneran las abstracciones antes que los seres. La piedad y la tolerancia tienen por lo tanto su lugar, pero forman parte de las intervenciones prácticas, de las reacciones inmediatas, de los gestos concretos, y no de los principios de la justicia o de los criterios sobre los que basar los juicios» (p. 15-16).

\section{Crítica de los valores implícitos en el acto mismo de juzgar las culturas}

¿No es en sí mismo reprensible juzgar las culturas ajenas?

«Ese parece ser, por lo menos, el consenso de nuestros contemporáneos ilustrados (en cuanto a los otros, evitan manifestarse en público)» (p. 16).

Quienes adoptan esta postura rechazan la comparación y jerarquización de las culturas, puesto que ello implica admitir la existencia de un esquema cultural universal según el cual se ordenarían todas las culturas. Cada cultura es universal en sí misma. Los seres humanos están determinados por su biografía, por sus condiciones materiales, por su pertenencia étnica. (¿Lo son hasta el punto de jamás poder liberarse?).

Todorov se muestra en desacuerdo con esta postura abstencionista. Entiende que «detrás del temor a jerarquizar y juzgar está el espectro de racismo»; que un discurso tan hiperdeterminista como éste no carece de consecuencias políticas: «si se convence a los hombres de que son esclavos, acabarán por serlo».

«Se dice que si se condenan los sacrificios humanos se corre el riesgo de parecer un campeón de la raza blanca. Y desde luego Buffon y Gabineau se equivocaban al concebir las civilizaciones en forma de una única pirámide cuya cúspide estaría ocupada por los rubios germanos o por los franceses, y la base, o mejor dicho el fondo o culo del recipiente, por los pieles rojas y los negros. Pero su error no consiste en haber afirmado que las civilizaciones son distintas y no obstante comparables, porque de lo contrario se cae en negar la unidad del género humano, lo que conlleva "riesgos y peligros" en absoluto menos graves; el error consiste en haber postulado la solidaridad de lo físico y lo moral, del color de la piel y de las formas adoptadas por la vida cultural» (p. 17).

\section{Todorov es partidario de comparaciones culturales puntuales.}

Entiende que no hay ninguna razón para renunciar a la universalidad del género humano; «debe serme posible decir no que tal cultura, tomada como un todo, es superior o inferior a tal otra (lo cual seguiría siendo ver una coherencia general), pero sí que tal rasgo de una cultura, sea de la nuestra o de otra ajena, tal comportamiento cultural es condenable o loable. Al tener demasiado en cuenta el contexto -histórico o cultural- se excusa todo; pero la tortura, para poner un 
ejemplo, o la escisión, por poner otro, no son justificables por el hecho de que se practiquen en el marco de tal o cual cultura concreta» (p. 18).

En todo caso, quienes han tomado conciencia del derecho y del deber de efectuar juicios interculturales, no han resuelto, por el mismo hecho, todas las dificultades que implica juzgar en este complicado campo.

Todorov nos ofrece una ilustración de estas dificultades, evocando el pensamiento de algunos filósofos franceses del pasado: Montaigne, Condorcet y Montesquieu.

\section{A) Montaigne.}

Es el representante del principio de la tolerancia y del relativismo radical. Para él es imposible elegir entre dos costumbres, puesto que no existe ninguna perspectiva neutral desde la que compararlas. «Cada cual llama barbarie a lo que no forma parte de su costumbre». Montaigne es un activo partidario del mito del buen salvaje.

Pero esta postura de tolerancia generalizada es insostenible. Se trata de una «postura intrínsecamente contradictoria, puesto que consiste en declarar al mismo tiempo que todas las actitudes son equivalentes y en preferir una a todas las demás: la propia tolerancia» (p. 18).

Además, es incompatible con el mito del buen salvaje: «si el salvaje es bueno, no sólo para sí mismo sino también a nuestros ojos, entonces la bondad es una cualidad transcultural. La barbarie deja de ser, pues, un defecto óptico: refiriéndose a los mismos "caníbales" que le proporcionan el pretexto para la definición relativista del término, afirma entonces que nosotros "los superamos en toda clase de barbarie"; pero quien dice "superar" compara y juzga» (p. 19).

«Por último, los tales salvajes sólo son "buenos" porque encarnan el ideal de Michel de Montaigne, el mundo de los valores griegos y romanos» (idem).

Conclusión:

«Aunque el impulso inicial de Montaigne sea generoso, su posición revierte en último término en un etnocentrismo inconsciente (contra el cual creía estar poniéndonos en guardia): se ve llevado a pronunciar juicios de valor en nombre de criterios absolutos, pero esos criterios no son más que la proyección acrítica de sus propias opiniones» (idem).

\section{B) Condorcet.}

Es universalista y se asume como tal; punto final de la tradición enciclopedista.

«Lejos de él toda veleidad de ocultar sus principios absolutos: en nombre de las Luces, de la razón universal, establece una escala única de las civilizaciones en cuya cima se encuentran "los pueblos más ilustrados, los más libres, los más exentos de prejuicios, los franceses y los angloamericanos" (es decir, los que acaban de realizar su Revolución); mientras que una "distancia inmensa" los separa "de la servidumbre de los indios, de 
la barbarie de los pueblos africanos, de la ignorancia de los salvajes"» (p. 19).

Obviamente, hoy muy pocos se atreverían a aceptar expresamente el punto de vista de Condorcet. Sin embargo, su discurso no tiene un espíritu racista: «no se contenta con constatar y juzgar, puesto que también dispone de un ideal para la vida sobre la tierra: que todos los hombres se conviertan en iguales; y se dirige así a los negros: "La Naturaleza os ha formado para que tengáis el mismo espíritu, la misma razón, las mismas virtudes que los blancos" ». Al contrario que los racistas, Condorcet no piensa que las diferencias físicas y las diferencias morales estén correlacionadas; es posible actuar sobre éstas últimas. El camino que conduce a tal igualación ascendente es la educación.

Aunque, en la práctica, esta concepción se tradujo en colonialismo: franceses y anglo-americanos civilizando al resto del mundo.

C) Montesquieu.

Representa una postura intermedia entre el relativismo de Montaigne y el universalismo de Condorcet. Es decir, representa la posibilidad de juzgar a las demás culturas y a la vez dejarlas en paz: el ideal al que accede una civilización cuando alcanza la madurez.

Montesquieu, en la línea de Montaigne, es un relativista y no se propone en mayor medida que él modificar el estado de cosas. Pero, al mismo tiempo, Montesquieu no pierde su fe en los principios universales de la justicia (El espíritu de las leyes).

Pero, el mismo Montesquieu se da cuenta que su posición constituye una paradoja: quienes no comparten este ideal, ¿no resultarán favorecidos por esta actitud pasiva? En Las cartas persas, refiriéndose a la tiranía que padecen las mujeres, sostiene: «el imperio que tenemos sobre ellas es una auténtica tiranía; el que nos lo hayan permitido sólo se debe a que tienen más ternura que nosotros $\mathrm{y}$, por lo tanto, más humanidad y más razón. Estas ventajas, que sin duda deberían procurarles la superioridad, de haber sido nosotros razonables, les ha hecho perderla, porque nosotros no lo somos. Cuanto más humanidad y razón tenemos, menos queremos tiranizar a los demás; pero más fácil les es a los otros tiranizarnos» (p. 21).

En resumen, ¿cuál es la solución a esta dificultades que plantea el juicio intercultural?

Todorov sostiene que aunque Montesquieu no la indica expresamente, podría ser que estuviese bien planteada implícitamente. Por tanto, hay que descubrirla. Sin embargo, Todorov tampoco la desvela, acogiéndose a la misma sentencia de Montesquieu: «No se trata de hacer leer sino de hacer pensar».

\section{4) ¿Cómo juzgar los contactos entre culturas (o su ausencia)? Interacción con los otros}

Con las referencias anteriores, Todorov aborda el problema central del cruzamiento entre culturas: ¿cómo juzgar la interacción con los otros?

En primer lugar, sostiene que no se puede concebir una cultura sin ninguna relación con las demás culturas: la identidad nace de la (toma de conciencia de la) diferencia; además, una cultura no evoluciona si no es a través de los contactos: lo 
intercultural es constitutivo de lo cultural. De ahí que, las sociedades que valoran más su aislamiento que sus contactos con otras sociedades, jamás llegan a practicarlo de manera absoluta.

Pero, debe entenderse que «ambas cosas (contactos y ausencia relativa de los mismos) son necesarias».

Por un lado, «los habitantes de un país disfrutan de un mejor conocimiento de su propio pasado, de sus valores y de sus costumbres, en la misma medida en que están abiertos a otras culturas» (p. 23).

La necesidad de un aislamiento relativo, por otro lado, la resume Lévi-Strauss: "De alcanzarse plenamente, la comunicación integral con el otro condena, a plazo más o menos corto, la originalidad de su creación y de la mía. Las grandes épocas creadoras fueron aquellas en las que la comunicación había llegado a ser suficiente para que los interlocutores alejados se estimularan, sin ser no obstante lo bastante frecuente y rápida para que los obstáculos, indispensables entre los individuos como entre los grupos se redujeran hasta el punto de que la excesiva facilidad de los intercambios igualara y confundiera su diversidad» (pp. 129).

Apertura y aislamiento son dos actitudes ampliamente documentadas. Aunque las de aislamiento sean más numerosas; el encierro resulta más fácil que la apertura.

La apertura requiere «un esfuerzo consciente e implica un deber ser distinto del mero ser».

El problema político-práctico es, aquí, eludir la elección entre malinchismo y xenofobia.

Todorov estima que la «mejor consecuencia del cruzamiento entre culturas suele consistir en la mirada crítica que uno vuelve hacia sí mismo; lo cual no implica en absoluto la glorificación de lo ajeno» (p. 28). Siguiendo a Northrop Frye, denomina «TRANSVALORACIÓN a esa vuelta sobre sí mismo de la mirada previamente informada por el contacto con otro», y sostiene «que constituye en sí misma un valor, mientras que lo contrario no lo es» (pp. 23).

El modelo lo encuentra en un campo particular y en uno de los primeros teóricos de la interacción cultural: en Goethe, el inventor del concepto de literatura universal.

Para Goethe la literatura universal no es el mínimo común denominador de las literaturas del mundo. «Lo que le interesaba eran precisamente las transformaciones que sufre cada literatura nacional en la época de los cambios universales. Y señala una doble vía a seguir. Por una parte, no es menester renunciar por completo a la propia particularidad, sino todo lo contrario: hay que ahondarla, por así decir, hasta descubrir en ella lo universal. (...) Por otra parte, de cara a la cultura extranjera, no hay que someterse, sino ver otra expresión de lo universal y, por lo tanto, buscar el modo de incorporarla: "Hay que aprender a conocer las particularidades de cada nación, con el fin de aceptarlas, que es precisamente lo que permite entrar en intercambio con ella: pues las particularidades de una nación son como su lengua y su moneda”.

El propio Goethe, el autor más influyente de la literatura alemana, tuvo, como es sabido, una incansable curiosidad por todas las demás culturas, próximas o lejanas: "Jamás he lanzado una mirada ni dado un paso en el extranjero", escribe en una carta, "sin la intención de conocer en sus formas más diversas lo universalmente humano, que está extendido y repartido por toda la tierra, y a continuación 
reencontrarlo en mi patria, reconocerlo y fomentarlo". El conocimiento ajeno sirve para el enriquecimiento propio» (p. 25).

Ahora bien, si lo «universalmente humano» que cabe descubrir en las diversas culturas que pueblan nuestro planeta no es un «mínimo común denominador», o una suerte de modelo estadístico, ¿será, entonces, el Espíritu Universal hegeliano, manifestándose en las diversas formas culturales de cada nación?

Parece que Todorov se muestra favorable a entender lo «universalmente humano» como un constructo histórico, siempre abierto y contradictorio, de la interacción de las culturas en los tiempos de la mundialización (Goethe), en un difícil equilibrio de aislamiento relativo (Lévi-Strauss) y de transvaloración (Northrop Frye). Tal es el campo de las mediaciones sociales.

Sit tibi terra levis, Tzvetan.

Vicente Baca Lagos

Universidad Complutense de Madrid vicbaca@ucm.es 